Pediatrics

\title{
Equitable approaches to reducing the prevalence of pediatric obesity: school nutrition policies and beyond
}

\author{
Emily B. Finn (iD ${ }^{1 凶}$, Amy Beck ${ }^{2}$ and Mona Sharifi ${ }^{1}$ \\ (c) The Author(s), under exclusive licence to Springer Nature Limited 2021
}

International Journal of Obesity (2021) 45:2289-2290; https://doi.org/10.1038/s41366-021-00924-0

The rising prevalence of overweight/obesity and refractory racial/ ethnic disparities demand the rapid implementation of innovative, comprehensive policy changes paired with rigorous evaluation to accelerate the broad adoption and prioritization of the most effective and equitable policies [1]. Sanchez-Vaznaugh et al. apply an equity lens to offer important insight into the additive effects of federal and state policies regarding in-school nutrition standards [2]. Specifically, they found that overweight/obesity prevalence among California 5th and 7th graders improved after the initiation of state-level policies regulating food and beverages sold in schools, with further improvement following federal policies regulating meals provided in schools. Although they highlighted severe and persistent racial/ethnic disparities, they observed greater improvements in overweight/obesity among Black and Latino children relative to other groups. The urgency of understanding the effectiveness of interventions for childhood overweight/obesity has never been higher, given alarming indications that prevalence of and disparities within pediatric overweight/obesity may be worsening during the SARS-CoV-2 pandemic [3].

Past research led by Sanchez-Vaznaugh et al. demonstrated that California state policies regulating foods and beverages sold in schools had a greater positive impact on pediatric overweight/ obesity among children at schools in socioeconomically advantaged versus disadvantaged neighborhoods [4]. It is, therefore, encouraging to see that the more recent state and federal policies examined in this issue were associated with a reduction in disparities and appear to have preferentially benefited children in populations disproportionately affected by overweight/obesity. Further research exploring how and why these policies yielded different impacts on these populations may provide important insight to inform future policy development.

The authors appropriately temper their conclusions by noting that school food policies, while important, are insufficient on their own to reduce disparities. Kumanyika developed a framework for designing and evaluating obesity prevention efforts to maximize impact on disparities [5]. The framework's four pillars-increasing healthy options, reducing deterrents, improving social and economic resources, and building on community capacitydemand comprehensive, multi-level interventions to change the policies, systems, and environmental factors rooted in structural racism, which drive disparities in overweight/obesity [6].

Promising evidence-based options to mitigate disparities in childhood overweight/obesity include efforts to reduce sugarsweetened beverage (SSB) intake, promote healthy behaviors through affordable summer programming, and modify the built environment in low-income neighborhoods. Despite policy measures enacted to limit SSB intake across various settings, the majority of 5-17 year-old drink SSB daily, with the highest intake among Latino and Black youth, a pattern which is likely driven by targeted marketing to these groups [7]. Equity-focused policies to replace children's SSB intake with water include: eliminating SSB marketing to children, SSB taxes, SSB warning labels, mandating the availability of water in schools and childcare settings, and revising federally-funded nutrition programs by restricting use of Supplemental Nutrition Assistance Program funds to purchase SSB coupled with incentives for fruit and vegetable purchases and eliminating juice allowances from the Special Supplemental Nutrition Program for Women, Infants, and Children [8]. Offering affordable structured summertime programming that encourages healthy behaviors, including healthier eating, more physical activity, and less screen time, may mitigate the accelerated weight gain observed among children during summer school breaks [9]. To best promote equity, such programming should be located within neighborhoods where children are at greatest risk of developing overweight/obesity. Last, children's built environments, including park accessibility, safety, and presence and quality of sidewalks, may protect against pediatric overweight/ obesity by facilitating no-cost physical activity. However, these benefits are modified by local contextual factors such as safety and the size and quality of recreational spaces [10]. Creative and accessible solutions, such as temporarily closing streets, may effectively increase children's physical activity [11]. Importantly, community-based interventions must be developed with community input and engagement to shape the planning process from the very beginning.

Cost is certainly an important consideration in intervention selection, and cost-effectiveness models have suggested the costsaving potential of three primary prevention interventions: an excise tax on SSB, eliminating tax deductions on unhealthy foods

\footnotetext{
${ }^{1}$ Department of Pediatrics, Yale School of Medicine, New Haven, CT, USA. ${ }^{2}$ Department of Pediatrics, University of California San Francisco, San Francisco, CA, USA. 凶email: e.finn@yale.edu
} 
marketed to children, and standards for food and drink sold in schools [12]. While an external stakeholder group advised the investigators on topics including equity, Gortmaker et al.'s simulation results are based on the US population as a whole. Models are needed that specifically examine differential costeffectiveness among populations disproportionately affected by overweight/obesity to guide identification of the most impactful, efficient, and equitable policies.

If policy changes are to have the desired impact on the obesity epidemic, policymakers should consider the wider lens of equity to ensure that policies will be most effective against the historic and ongoing structural racism driving many of the disparities seen in pediatric overweight/obesity. While school nutrition policies are certainly needed, and may have somewhat narrowed disparities in pediatric overweight/obesity, they alone are insufficient and must be part of a broader policy package developed specifically to eliminate disparities.

\section{REFERENCES}

1. Fryar CD, Carroll MD, Afful J. Prevalence of overweight, obesity, and severe obesity among children and adolescents aged 2-19 years: United States, 1963-1965 through 2017-2018. NCHS Health E-Stats. 2020.

2. Sanchez-Vaznaugh EV, Matsuzaki M, Braverman $P$, Acosta ME, Alexovitz K, Sallis $J F$, et al. School nutrition laws in the US: do they influence obesity among youth in a racially/ethnically diverse state? Int J Obes (Lond). 2021.

3. Jenssen BP, Kelly MK, Powell M, Bouchelle Z, Mayne SL, Fiks AG. COVID-19 and changes in child obesity. Pediatrics. 2021;147:e2021050123.

4. Sanchez-Vaznaugh EV, Sánchez BN, Crawford PB, Egerter S. Association between competitive food and beverage policies in elementary schools and childhood overweight/obesity trends: differences by neighborhood socioeconomic resources. JAMA Pediatr. 2015;169:e150781.

5. Kumanyika SK. A framework for increasing equity impact in obesity prevention. Am J Public Health. 2019;109:1350-7.

6. Bleich SN, Ard JD. COVID-19, obesity, and structural racism: understanding the past and identifying solutions for the future. Cell Metab. 2021;33:234-41.

7. Russo RG, Northridge ME, Wu B, Yi SS. Characterizing sugar-sweetened beverage consumption for US children and adolescents by race/ethnicity. J Racial Ethnic Health Disparities. 2020;7:1100-16.

8. Krieger J, Bleich SN, Scarmo S, Ng SW. Sugar-sweetened beverage reduction policies: progress and promise. Ann Rev Public Health. 2021;42:439-61.
9. Tanskey LA, Goldberg J, Chui K, Must A, Sacheck J. The state of the summer: a review of child summer weight gain and efforts to prevent it. Cur Obesity Reports. 2018;7:112-21.

10. Vargas CM, Stines EM, Granado HS. Health-equity issues related to childhood obesity: a scoping review. J Public Health Dent. 2017;77:S32-s42.

11. Umstattd Meyer MR, Bridges CN, Schmid TL, Hecht AA, Pollack Porter KM. Systematic review of how play streets impact opportunities for active play, physical activity, neighborhoods, and communities. BMC Public Health. 2019;19:335.

12. Gortmaker SL, Wang YC, Long MW, Giles CM, Ward ZJ, Barrett JL, et al. Three interventions that reduce childhood obesity are projected to save more than they cost to implement. Health Affairs (Project Hope). 2015;34:1932-9.

\section{ACKNOWLEDGEMENTS}

This work was supported in part by the National Heart, Lung, and Blood Institute (R01HL151603 and K12HL138037), the National Institute on Minority Health and Health Disparities (R01MD014853), and the National Institute of Child Health and Human Development (1K23HD080876-01A1) of the National Institutes of Health. The content is solely the responsibility of the authors and does not necessarily represent the official views of the National Institutes of Health.

\section{AUTHOR CONTRIBUTIONS}

All three authors (EBF, $A B, M S)$ conceived of the work that led to the submission. EBF led the manuscript drafting, all three authors collaboratively revised the manucsript. All three authors approved the final manuscript and agree to be accountable for all aspects of the work. EBF had final responsibility for the decision to submit for publication.

\section{COMPETING INTERESTS}

The authors declare no competing interests.

\section{ADDITIONAL INFORMATION}

Correspondence and requests for materials should be addressed to E.B.F.

Reprints and permission information is available at http://www.nature.com/ reprints

Publisher's note Springer Nature remains neutral with regard to jurisdictional claims in published maps and institutional affiliations. 